\title{
Estudo Comparado da Gestão das Visitações nos Parques Estaduais Turísticos do Alto da Ribeira (PETAR) e Intervales (PEI)
}

\section{Comparative Study of Tourism Management in State Parks Alto da Ribeira (PETAR) and Intervales (PEI)}

\section{Estudio Comparativo de la Gestión de los Parques Estaduales Alto Ribeira (PETAR) y Intervales (PEI)}

Gilberto Sarfati ${ }^{1}$

Nara Nanae Sano ${ }^{2}$

\section{Resumo}

O objetivo primário desta pesquisa é investigar porque dois parques estaduais relativamente semelhantes (PETAR e PEI) apresentam graus de conservação tão distintos. A hipótese central é que as diferenças podem ser explicadas em função das gestões diferentes, ou seja, o PEI é mais conservado que o PETAR, pois sua gestão é conduzida pela Fundação Florestal com a participação da comunidade local através de uma cooperativa. A análise dos dados e do resultado da pesquisa de campo nos leva a concluir que o PETAR está sofrendo um processo de deterioração de suas cavernas abertas à visitação e de seu entorno fruto do turismo desordenado, configurando assim a incidência da tragédia dos comuns. Já no caso do PEI foi constatada uma visitação mais controlada e limitada e, portanto, um grau de preservação do complexo turístico bastante superior. Conclui-se que o modelo de gestão no qual o PEI é vinculado a Fundação Florestal ajuda a explicar o melhor grau de conservação do parque em relação ao PETAR administrado pelo Instituto Florestal.

Palavras-Chave: PETAR; PEI; gestão de visitações; turismo sustentável; tragédia dos comuns.

1 Professor do Departamento de Administração e de Recursos Humanos da FGV-EAESP. E-mail: gilberto@sarfati.com.br

2 Doutora em Geografia Física pela Universidade de São Paulo. E-mail: nara@sarfati.com.br. 


\begin{abstract}
The primary objective of this research is to investigate why two state parks which are relatively similar (PETAR and PEI) have such different degrees of conservation. The central hypothesis is that differences can be explained on the basis of differences on managements. PEI is the best preserved than PETAR because their management is conducted by the Forest Foundation with the participation of the local community through a cooperative. Data analysis and results of field research leads us to conclude that PETAR is undergoing a process of deterioration of their caves open to visitors and its surroundings result of chaotic tourism, thus creating the effect of the tragedy of the commons. In the case of PEI was found a more controlled and limited visitation, and therefore a degree of preservation of the park much higher. We conclude that the management model in which the PEI is bound to Forest Foundation helps to explain the best grade of conservation of the park over the PETAR managed by the Forestry Institute.
\end{abstract}

Keywords: PETAR; PEI; tourism management; sustainable tourism; tragedy of commons.

\title{
Resumen
}

El objetivo principal de este estudio es investigar por qué dos parques estaduales que son relativamente similares (PETAR y PEI) disponen de diferentes grados de conservación. La hipótesis central es que las diferencias se pueden explicar sobre la base de diferentes manejos, es decir, PEI es mejor conservado que PETAR debido a que su gestión se lleva a cabo por la Fundación Forestal, con la participación de la comunidad local por medio de una cooperativa. El análisis de datos y los resultados de la investigación de campo nos lleva a la conclusión de que PETAR está experimentando un proceso de deterioro de sus cuevas abiertas al público y sus alrededores por razón de un turismo no regulado, creando así el efecto de la tragedia de los comunes. En el caso de PEI se encontró una visita más controlada y limitada, y por lo tanto un grado de preservación del parque mucho más alto. Se concluye que el modelo de gestión en el que PEI es manejado por la Fundación Forestal ayuda a explicar el mejor grado de conservación del parque sobre el PETAR administrado por el Instituto Forestal.

Palabras claves: PETAR; PEI; gestión de turismo; turismo sostenible; tragedia de los comunes. 


\section{Introdução}

As visitas às unidades de conservação, em especial aos parques estaduais, tornaram-se uma atividade altamente disseminada nas últimas décadas do século $\mathrm{XX}$, ocasionando a intensificação das visitas aos ambientes naturais protegidos.

Grande parte desse fenômeno deve ser atribuída à expansão do ecoturismo. $\mathrm{O}$ ecoturismo, além de uma atividade recreativa em ambientes naturais, abrange em sua conceituação a experiência educacional interpretativa, a valorização das culturas tradicionais locais e do desenvolvimento sustentável (KINKER, 1999), contudo, pode vir a causar impactos negativos sobre o meio ambiente caso suas atividades não sejam bem administradas.

Dentro desse contexto, os Parques Estaduais, cujas áreas são de proteção integral de ambientes naturais, permitem visitas para fins recreativos e educacionais, ou seja, para o uso indireto dos seus recursos naturais e tornaram-se destinos de milhares de ecoturistas ávidos por um contato com a natureza e atraídos pela possibilidade de vivenciar um espaço diverso do meio ambiente urbano.

Por permitir visitações, os Parques Estaduais constituem importante objeto de estudo já que integram a proteção ambiental e o desenvolvimento econômico local (WEARING; NEIL, 2001, p.70). Nesse contexto, o Parque Estadual Intervales (PEI) e o Parque Estadual Turístico do Alto Ribeira (PETAR), ambos localizados no Estado de São Paulo, na região do Vale do Ribeira, estão presenciando a explosão do ecoturismo, recebendo um número cada vez maior de visitantes.

Se, por um lado, a região do Vale do Ribeira caracteriza-se por amplos e preservados ambientes naturais, por outro, apresenta-se como a região mais empobrecida do Estado de São Paulo. Assim o PETAR e o PEI poderiam representar um fator importante no desenvolvimento e o conseqüente aumento da qualidade de vida da região.

Os manejos dos Parques Estaduais do Estado de São Paulo são efetuados mediante a obediência aos mesmos preceitos legais e regulamentos existentes sobre a matéria. Contudo, existem diferenças na condução do modo de gerir o ecoturismo dentro dos parques. De fato, o 
PETAR e o PEI, embora sob a tutela do mesmo ente federal (o Estado de São Paulo) e subordinado à Secretaria do Meio Ambiente do Estado de São Paulo (SMA), têm diferenças claras no modo de gerir. Assim, enquanto o primeiro é gerido pela Fundação Florestal (FF) e apresenta-se razoavelmente conservado, o segundo, gerido pelo Instituto Florestal (IF), apresenta uma conservação menor. Ambos enfrentam, em maior ou menor grau, dificuldades comuns relacionadas à gestão das visitações.

O objetivo primário desta pesquisa é investigar porque dois parques estaduais relativamente semelhantes (PETAR e PEI) apresentam graus de conservação tão distintos. As variáveis consideradas nesta análise foram: as formas de gestão, os recursos humanos disponíveis e os fluxos de visitação.

A hipótese central é que as diferenças podem ser explicadas em função das gestões diferentes, ou seja, o PEI é mais conservado que o PETAR, pois sua gestão é conduzida pela Fundação Florestal com a participação da comunidade local através de uma cooperativa. Tal arranjo institucional acaba, ao mesmo tempo, resolvendo um problema de responsabilidade estatal de conservação do meio ambiente natural e visitação pública com fins educacionais; com o interesse econômico da comunidade local. Por outro lado, no PETAR, a falta de coordenação entre o interesse público e o econômico tem levado a exploração absolutamente desordenada do parque.

O método básico de pesquisa adotado foi a análise exploratória através da contextualização jurídica dos parques e trabalho de campo onde foram observadas as condições dos parques e entrevistados turistas e guias/monitores.

Ou seja, foi realizado o estudo comparativo da gestão dos dois Parques Estaduais inseridos na mesma região do Estado de São Paulo e com características geográficas semelhantes: o PETAR e o PEI. Ambos os parques possuem grandes dimensões de áreas e somente parte de sua área total é aberta às visitações. Diante desse aspecto, somente as áreas de visitação do PETAR e do PEI foram objetos de comparação.

O estudo conclui que o PEI é melhor conservado que o PETAR dado o modelo jurídico de administração no qual a vinculação a uma fundação ao invés de um órgão (IF) permite mais 
flexibilidade na gestão diária do parque. Além disso, a infraestrutura de hospedagem do PEI é relativamente pequena e não há outras hospedagens na proximidade o que também acaba contribuindo para a preservação do parque dado um número relativamente pequeno de visitantes.

\section{Fundamentação Teórica e Conceitual}

O PEI e o PETAR estão localizados no contínuo ecológico do Paranapiacaba, o que constitui um dos pontos de semelhança desses dois objetos de estudo. Entende-se como contínuo ecológico as grandes extensões de habitat naturais, com livre fluxo de matéria e energia, ou seja, grandes corredores que interligam as unidades de conservação ao longo do Brasil e do continente americano - como é o caso da reserva da biosfera da Mata Atlântica. Essas áreas contíguas abrigam espécies em maior número e em maiores populações, tornando-as mais resistentes a impactos externos, como catástrofes naturais ou provocadas (SÃO PAULO, 1998, p.8).

Esses grandes corredores ecológicos, de acordo com o SNUC - Sistema Nacional de Unidades de Conservação são porções de ecossistemas naturais ou seminaturais, ligando unidades de conservação, que possibilitem entre elas o fluxo de genes e o movimento da biota, facilitando a dispersão de espécies e a recolonização de áreas degradadas, bem como a manutenção de populações que demandam para sua sobrevivência áreas com extensão maior do que aquela das unidades individuais.

A gestão de visitações dentro de um parque estadual pode ter como diretriz os princípios que norteiam o conceito de desenvolvimento sustentável. Considerando-se a soma dos conceitos de desenvolvimento - como a melhoria de condições de vida das populações - e sustentabilidade - entendida dentro de parâmetros econômicos e ambientais, temos que o desenvolvimento sustentável refere-se à prática de atividades que possibilitem, com viabilidade econômica, a utilização dos recursos naturais de modo e em ritmo tais que não levem, a longo prazo, a diminuição da diversidade biológica e dos componentes do ambiente físico, mantendo assim seu potencial para atender às necessidades e aspirações das gerações 
presentes e futuras (SÃO PAULO, 1998, p.9), sendo essencial, portanto, o uso sustentável, ou seja, a exploração do ambiente de maneira a garantir a perenidade dos recursos ambientais renováveis e dos processos ecológicos, mantendo a biodiversidade e os demais atributos ecológicos, de forma socialmente justa e economicamente viável.

O conceito de desenvolvimento sustentável engloba claramente o meio ambiente, as pessoas e os sistemas econômicos (SWARBROOKE, 2000, p.3) e seus princípios são, em sua maior parte, coincidentes com os do ecoturismo que por sua vez é um componente essencial daquele, sendo a conservação, a preservação e a proteção ao meio ambiente natural uma delas.

Há alguns anos, o termo ecoturismo e os princípios que norteiam sua atividade não existiam. Ceballos-Lacuráin (2005, p.25) observa que o fenômeno em si não é novo e cita viajantes naturalistas como Humboldt, Darwin, Bates e Wallace. Suas experiências, porém, foram "tão isoladas que não produziram benefícios socioeconômicos significativos para os lugares visitados, e nem as atividades desenvolvidas pareciam ter a intenção de ser um meio para a conservação de áreas naturais, de culturas nativas ou de espécies em perigo de extinção".

O ecoturismo tem como compromisso a organização de um turismo capaz de promover o desenvolvimento dentro de critérios ambientais que garantam a manutenção de sua biodiversidade (MACHADO, 2005, p.24), o que a aproxima das atividades norteadas pelos princípios perseguidos pelo turismo sustentável.

A conceituação do ecoturismo abrange ampla gama de elementos que o caracterizam (WEARING; NEAL, 2001, p.1) dando margem a diversas definições com alguns pontos em comum. KINKER (1999, xxii) diz que se trata de um segmento do turismo de natureza, abrangendo em sua conceituação a experiência educacional interpretativa, a valorização das culturas tradicionais locais, a promoção da conservação da natureza e do desenvolvimento sustentável.

De acordo com The Ecotourism Society (HAWKINS; KAHN, 2001) o ecoturismo é "a viagem responsável a áreas naturais, visando preservar o meio ambiente e promover o bemestar da população local". 
Doinicar, Crouch e Long (2008) observam que o ecoturismo depende de um turista que tenha o perfil de amigável ao meio ambiente. De acordo com a pesquisa deles este perfil está fortemente associado à educação universitária, interesse em aprender e preocupação com o meio-ambiente.

De acordo com Ruschmann (1997), o ecoturismo produz impactos nas áreas visitadas e suas conseqüências, sejam elas benéficas ou negativas, estão diretamente relacionadas com a forma como são organizados e realizados seu planejamento, implementação e monitoramento. São impactos negativos causados pelo ecoturismo, entre outros, a alteração da paisagem pela implantação de construções e infraestrutura; consumo excessivo dos recursos naturais e estímulo ao consumo de souvenirs produzidos a partir de elementos naturais escassos, podendo levar ao seu esgotamento; produção excessiva de lixo e resíduos sólidos e efluentes líquidos; desequilíbrios dos ecossistemas naturais pela introdução de espécies exóticas de animais e plantas; surgimento de construções mal planejadas e de favelas; aumento do custo de vida devido à elevação de preços de imóveis e de itens de consumo; perda de valores tradicionais em conseqüência da introdução de novas culturas; aumento da população local devido à geração de fluxos migratórios para áreas de concentração turística.

Apesar de ser um conceito amplo, aberto a inúmeras interpretações, pode-se definir o turismo sustentável como sendo uma das formas de turismo que satisfaçam as necessidades dos turistas e das comunidades locais, sem comprometer a capacidade das futuras gerações de satisfazerem suas próprias necessidades (SWARBROOKE, 2000, p.19 e 71). Ou seja, são observados os mesmos princípios norteadores do desenvolvimento sustentável, que são a eficiência econômica e a conservação da natureza, culminando na justiça social e na conseqüente equidade da população anfitriã (RODRIGUES, 2003).

Para Gossling, Hall e Weaver (2009) o desenvolvimento do turismo sustentável é um processo que atende as necessidades das gerações presentes e futuras de produtores e consumidores do turismo sem prejudicar a resiliência das empresas de turismo ou a integridade dos sistemas sociais e naturais dos quais eles dependem. 
Knafou (1996) critica a inscrição do desenvolvimento sustentável no campo da racionalidade econômica, rejeitando a ideia de que se deve limitar o número de turistas a fím de preservar os recursos econômicos, pois defende que se trata de um argumento baseado em mitos de que o turismo devora e acaba com as paisagens que consome. Sustenta que "ninguém é capaz de definir o limiar ou ainda o que poderia ser a noção esfumaçada de "desenvolvimento sustentável".

Segundo Briassoulis (2002) o turismo em geral pode ser identificado com o clássico problema dos recursos comuns já que é um bem não exclusivo, ou seja, é impossível impedir o consumo das pessoas; e rival, onde o consumo de uma pessoa impede o consumo da outra. O problema do turismo comum é complexo, pois é objeto de usos de diversos grupos diferentes inclusive daqueles que trabalham ou exploram comercialmente determinado espaço geográfico. $\mathrm{O}$ turismo é altamente volátil e sazonal em comparação ao uso do espaço por outros grupos.

Ao mesmo tempo, considerando que o turista não depende economicamente daquele lugar ele é potencialmente destrutivo, ou seja, o turista vem em massa ao lugar, usa em excesso os recursos locais na temporada e depois vai embora deixando o problema do esgotamento de recursos para aqueles que dependem economicamente do lugar. Ou seja, o turista é um freerider (carona) que consome os recursos locais sem ter que pagar a conta pela destruição do meio-ambiente.

Desta forma, por definição, a tragédia dos comuns do turismo está atrelada a sua insustentabilidade. Ou seja, se não há algum tipo de gestão do turismo neste local, inevitavelmente ele será destruído. Assim, a questão do uso excessivo do turismo passa ser não de se há ou não um dano ao meio ambiente, pois sempre há, mas sim, quanto tempo e turistas são necessários para se causar danos irreversíveis naquele lugar. Neste sentido, o pior problema do turismo free-rider é o efeito cumulativo onde efeitos incrementais são gerados por decisões independentes que manifestam seus efeitos gradualmente no tempo até que seja ou muito tarde ou ineficiente o controle de suas causas (BRIASSOULIS, 2002).

A clássica falha de mercado da tragédia dos comuns pode ser resolvida de diversas formas que freqüentemente também são aplicadas ao turismo como propriedade privada, estatização ou 
até concessão a uma determinada comunidade, ou seja, sempre há uma interferência para lidar com a tragédia. No caso do turismo, a privatização de determinadas áreas ou o estabelecimento de parques turísticos governamentais são frequentemente a solução adotada no mundo inteiro para este problema. Assim, uma vez estabelecido algum tipo de regime de gestão do território aumenta a probabilidade da execução de um turismo sustentável já que o gestor da área determina as limitações da exploração dos recursos.

\section{Caracterização da Área de Estudo}

O PETAR e o PEI estão localizados ao sul do Estado de São Paulo (figura 1) e formam parcela importante da Reserva da Biosfera da Mata Atlântica. Suas áreas compõem o Contínuo Ecológico de Paranapiacaba (com mais de 120.000 ha) juntamente com as áreas do Parque Estadual Carlos Botelho (PECB), Estação Ecológica Xitué (EEcX), a Zona de Vida Silvestre da Área de Proteção Ambiental da Serra do Mar e a zona núcleo da Reserva da Biosfera da Mata Atlântica, configurando significativos trechos protegidos de Mata Atlântica (SÃO PAULO, 1998).

O PETAR localiza-se no Estado de São Paulo, no Alto Vale do Rio Ribeira de Iguape, abrangendo terras o município de Apiaí e Iporanga, a cerca de $350 \mathrm{~km}$ da capital. Posiciona-se entre as coordenadas $24^{\circ} 31^{\prime}$ e $24^{\circ} 34^{\prime}$ de latitude sul e $48^{\circ} 40^{\prime}$ e $48^{\circ} 44^{\prime}$ de longitude oeste (ALLEGRINI, 1999).

O acesso ao Núcleo de visitação denominado Santana, partindo-se da capital, pode ser feito por duas rotas:

a. Pela Rodovia Castelo Branco até a cidade de Tatuí e, a partir dessa cidade em direção às cidades de Itapetininga, Capão Bonito, Guapiara e Apiaí (total de 324 km). De Apiaí, segue-se à Iporanga em estrada de terra $(23 \mathrm{~km})$.

b. Outra alternativa de acesso é pela BR-116 (Rodovia Régis Bittencourt) até a cidade de Jacupiranga. Segue-se a partir dessa cidade para Eldorado e Iporanga (total de $312 \mathrm{~km}$ ). De Iporanga até o Núcleo Santana são mais 16 km de estrada. 
O Contínuo Ecológico de Paranapiacaba constitui um extenso corredor coberto por floresta densa, que possibilita o trânsito de grande quantidade de espécies animais e a sua conseqüente proteção (SÃO PAULO, 2000).

\section{MAPA DE LOCALIZAÇÃO PETAR - PEI}

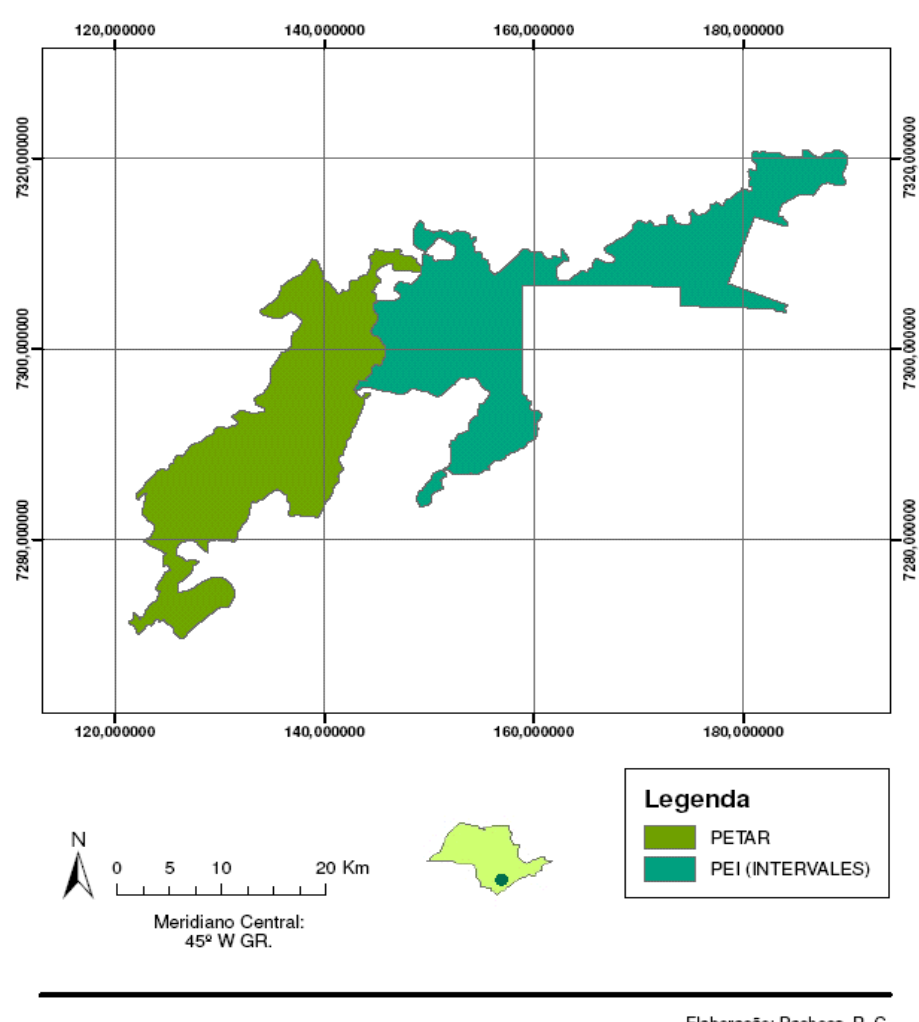

Base Cartográfica: Atas das Unidades de Conservação Ambiental do Estado de São Paulo, 2000.

Figura 1 - Mapa localização PETAR - PEI

Foi criado pelo Decreto $\mathrm{n}^{\mathrm{o}} 32.283$ de 19 de maio de 1958 com o nome de PEAR - Parque Estadual do Alto Ribeira, mas a Lei no 5.973 de 1960 alterou seu nome para PETAR a fim de considerar suas terras de preservação permanente e inalienáveis. Sua área tem 35.712 ha e a sua criação foi motivada pelo objetivo de resguardar os atributos naturais da região. A 
exuberante Mata Atlântica, a sua fauna característica e, principalmente, o seu rico patrimônio espeleológico.

Nos primórdios da criação desta Unidade de Conservação o Instituto Geográfico e Geológico do Estado de São Paulo (IGG) estabeleceu uma base de pesquisa e fiscalização sobre terras devolutas do Estado destinadas à sua administração, o Núcleo Caboclos, cuja vigilância e administração do turismo nas grutas eram feitas por alguns de seus funcionários. A implantação efetiva do PETAR deu-se na década de 1980, com a desapropriação das terras e a manutenção de três funcionários em seu quadro funcional.

O PETAR possui quatro núcleos de visitação abertos ao público:

- Núcleo Santana, localizada no vale do rio Betari. Possui diferentes opções de roteiros de visitação, como a caverna Santana, a trilha do rio Betari - na qual é possível visitar a caverna da Água Suja, Torre de Pedra e cachoeiras do Betarizinho e Andorinhas, e a trilha do Morro Preto-Couto - grutas do Morro Preto, cachoeira do Couto e caverna do Couto.

- Núcleo Caboclos, localizado na região central do PETAR, em que é possível visitar as cavernas Sete Reis e Maximiano, além de outros atrativos.

- Núcleo Ouro Grosso, localizado próximo ao bairro da Serra, no Vale do Betari.

- Núcleo Casa de Pedra, localizado no vale do rio Iporanga, dá acesso ao pórtico de $215 \mathrm{~m}$ de altura Casa de Pedra.

No PETAR há 50 trabalhadores dentre guardas-parque, monitores e outros. Além desses funcionários, há os guias locais autônomos que são em torno de 100, porém, em virtude da sazonalidade das visitações, concentradas nas férias de verão, principalmente no mês de dezembro, os guias autônomos possuem outra ocupação.

Já o PEI localiza-se no Estado de São Paulo, entre a serra de Paranapiacaba e o Vale do Ribeira, abrangendo partes dos municípios de Ribeirão Grande, Eldorado Paulista, Guapiara, Iporanga e Sete Barras. Posiciona-se entre as coordenadas $24^{\circ} 12^{\prime}$ a $24^{\circ} 25^{\prime}$ de latitude sul e 4803' e 48³0'de longitude oeste (SÃO PAULO, 1998). 
$\mathrm{O}$ acesso à entrada principal e a sede do parque, partindo da capital, dá-se pela Rodovia Castelo Branco até Tatuí, e SP-181 até Ribeirão Grande, seguindo-se por mais $35 \mathrm{~km}$.

O Governo do Estado de São Paulo, através do Decreto $n^{\circ} 40.135$ de 8 de junho de 1995, transformou as terras da Fazenda Intervales, com 38.356 ha, e as glebas de terras devolutas chamadas Xiririca A e B, com 11.532 ha, totalizando área de 49.888 ha em parque estadual. Mas o Decreto $\mathrm{n}^{\circ} 44.293$ de 4 de junho de 1999 excluiu parte das glebas de Xiririca já que os governos federal e estadual reconheceram tais áreas como de propriedade definitiva dos remanescentes das comunidades dos quilombos. Desta forma, o território atual do parque é de aproximadamente 42.000 hectares. É administrado pela Fundação Florestal desde 1987 (SÃO PAULO 1998).

Sua criação teve o escopo de proteger as extensas áreas de mananciais, os sítios espeleológicos significativos e as encostas com declividades altas da Serra de Paranapiacaba cobertas pela Mata Atlântica.

O Parque Estadual Intervales possui 41,7 mil hectares e contém aproximadamente 60 cavernas, dos quais apenas 15 estão abertas à visitação, 25 roteiros de visitação, 13 cachoeiras e 2 mirantes (SÃO PAULO, 1998).

No PEI há 55 pessoas trabalhando no parque, dentre guardas-parque, agentes de recursos ambientais, técnicos de recursos ambientais e o assessor de direção executiva. Além desses funcionários, há estagiários e também os cooperados que cuidam da hospedaria, do restaurante e da recepção.

\section{O Modelo de Gestão do PETAR e do PEI}

O PETAR e o PEI estão submetidos à Secretaria de Estado do Meio Ambiente de São Paulo (SMA), que é um órgão seccional do Sistema Nacional do Meio Ambiente do Estado de São Paulo (SISNAMA) e também um órgão central do Sistema Estadual do Meio Ambiente (SISEMA). São imensas as dimensões das áreas naturais protegidas do Estado de São Paulo 
sob a responsabilidade da SMA. Para atingir organização e eficiência em sua administração, é necessário descentralizar e desconcentrar as atividades administrativas da SMA em outros órgãos, criando um sistema cuja estrutura seja articulada e coordenada.

O PETAR é gerido pelo Instituto Florestal (IF) enquanto o PEI pela Fundação Florestal (FF). O fato do IF ser um órgão público e a FF uma fundação pública implica em uma série de diferenças que esclarecem, em parte, os modos diferentes de gerir seus respectivos parques.

Órgão público ou órgão administrativo "é uma unidade de atuação, que engloba um conjunto de pessoas e meios materiais ordenados para realizar uma atribuição predeterminada" (MEDAUAR, 1996, p.56); seguindo a escala hierárquica, o órgão inferior (ou subordinado) IF é uma parte do órgão superior da SMA e ambos são integrantes da estrutura da Administração Pública do Estado de São Paulo. Quanto às normas, o IF é regido sempre por normas de direito público, que incluem, por exemplo, as normas de licitação.

Já a fundação pública "é uma entidade dotada de personalidade jurídica de direito privado, sem fins lucrativos, criada em virtude de autorização legislativa, para o desenvolvimento de atividades que não exijam execução por órgãos ou entidades de direito público, com autonomia administrativa, patrimônio próprio gerido pelos respectivos órgãos de direção, e funcionamento custeado por recursos da União e outras fontes"3.

Não há subordinação hierárquica entre a FF e a SMA, apenas tutela administrativa, pois a FF é dotada de personalidade jurídica própria, autonomia administrativa, patrimônio próprio. É custeada com recursos do estado de São Paulo e além de outros recursos oriundos de outras fontes, como a venda de sementes. Caso haja lucro com suas atividades, deverá ser revertida para os fins da própria entidade. Possui quadro próprio de pessoal e sua estrutura administrativa é internamente hierarquizada. No tocante às normas, sua atuação é regida principalmente pelo direito público, não obstante a aplicação de algumas normas de direito privado.

\footnotetext{
${ }^{3}$ Decreto-lei 200/67, art. $5^{\circ}$, inciso IV.
} 
Ressalte-se que as normas de licitação e contratos administrativos devem ser respeitadas pela FF, além da dependência de aprovação em concurso público para o ingresso de funcionários, independente do regime trabalhista. Além disso, o Tribunal de Contas faz a fiscalização financeira, orçamentária, patrimonial e contábil, e a Assembléia Legislativa pode fiscalizar e controlar os atos editados pela FF.

\section{Metodologia}

O método utilizado foi a pesquisa exploratória e o trabalho de campo em ambos os parques. As técnicas de pesquisa envolvidas no método do processo exploratório do tema são a pesquisa bibliográfica, a pesquisa documental e a pesquisa de campo.

Assim, a pesquisa envolveu análise documental relativa à legislação que afeta os parques e a caracterização jurídica da gestão dos mesmos, observação dos parques e entrevistas em questionários estruturados junto a turistas e guias/monitores.

Desde a formatação do questionário até a análise prévia dos resultados, foram seguidas as seguintes etapas, que constituem as orientações de MARANGONI (2005): preparação prévia, elaboração de questionário em gabinete, aplicação-teste e respectiva avaliação, nova aplicação, tabulação dos dados e a elaboração de tabelas e a análise dos resultados.

O trabalho de campo foi realizado entre os dias 17 a 19 de dezembro de 2009 e 21 a 22 de dezembro de 2009 no PEI e nos dias 23 a 25 de dezembro de 2009 no PETAR. Ambos os questionários, para os visitantes e guias/monitores, possuem 9 quesitos que correspondem às variáveis da pesquisa.

As questões foram elaboradas à partir da pesquisa bibliográfica, sites na internet, artigos acadêmicos e uma visita de reconhecimento prévio a cada um dos parques. As questões para os turistas visaram capturar o perfil dos visitantes, o processo de visitação, a percepção sobre o trabalho de guias/monitores e percepção sobre serviços e estado de conservação do parque. Já as questões para os guias/monitores visaram capturar o perfil da relação do monitor com o 
parque, incluindo anos de trabalho, regime de trabalho, treinamento e relação com gestores do parque.

No total responderam ao questionário 20 visitantes de cada parque, totalizando 40 visitantes e; 25 guias/monitores, sendo 15 do PETAR e 10 do PEI. A amostra de turistas entrevistados é de conveniência, não probabilística, escolhida aleatoriamente ao longo das horas disponíveis de visitação, sempre no começo/fim das trilhas dos parques. O questionário foi aplicado diretamente pelos pesquisadores. A amostra aleatória implica que não necessariamente toda a população seja proporcionalmente representada. Os monitores também responderam os questionários no início/fim das trilhas. No caso dos guias/monitores, a amostra do PETAR foi aleatória enquanto que no PEI representa toda a população.

A percepção destas duas populações foi utilizada para capturar em campo os efeitos dos modelos de gestão nos atores turísticos. Os dados compilados foram avaliados apenas através de tabelas de freqüência.

\section{Análise dos Resultados}

Conforme o gráfico 1, entre os turistas entrevistados, 50\% possuíam nível superior no PETAR contra $80 \%$ no PEI. Ainda $30 \%$ no PETAR tinham até primeiro grau enquanto que não foram entrevistados turistas com menos que o segundo grau no PEI.

A diferença no nível de educação dos entrevistados pode ser explicada parcialmente pelo fato de que não há divulgação ostensiva do PEI e as visitas são previamente agendadas via telefone e quase sempre o visitante hospeda-se dentro das acomodações do parque, uma vez que não há hospedagens nas cercanias do PEI.

Por outro lado, no caso do PETAR, o acesso é mais facilitado o que faz com que pessoas venham passar o dia no parque ou que cheguem ao local em ônibus de excursão. Desta forma, observa-se assim um perfil um pouco mais eclético em comparação ao caso do PEI. Ainda assim há um número considerável de visitantes com nível universitário que tende a ser o 
visitante ecoturista que permanece mais tempo na cidade ocupando as pousadas da região. Note-se também que alguns daqueles que têm primeiro grau completo ainda são jovens estudantes secundaristas um perfil de visitante que se encontra mais raramente no PEI (a não ser em excursões organizadas pelas escolas).

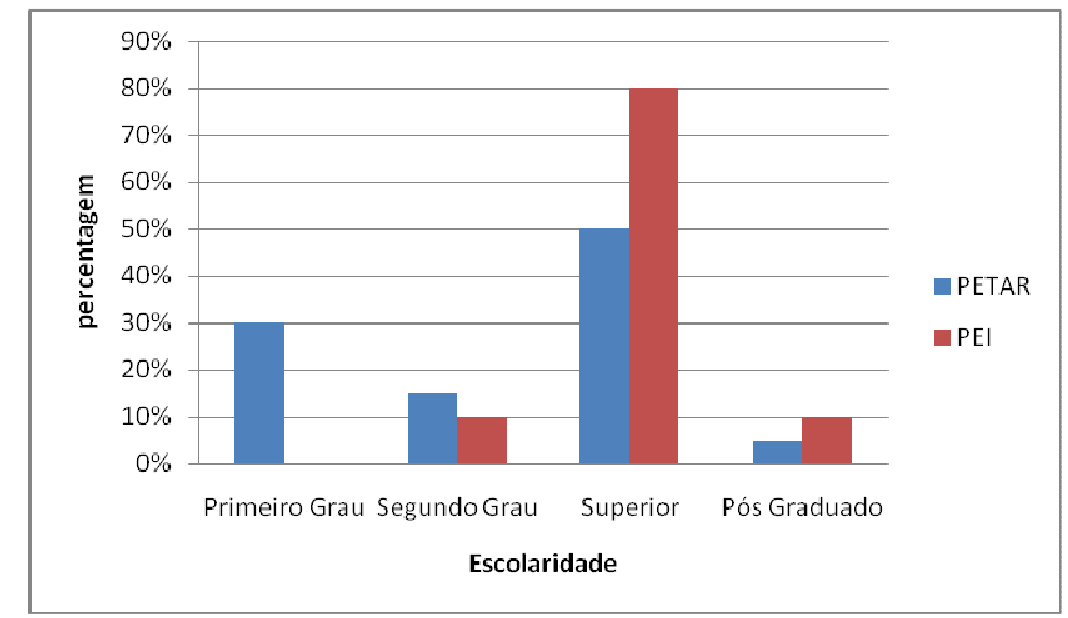

Gráfico 1 - Grau de Escolaridade dos Entrevistados no PETAR e PEI Fonte: Dados da pesquisa

Entre os entrevistados, $90 \%$ dos turistas do PETAR afirmaram que percorreram trilhas e visitaram cavernas contra $100 \%$ dos turistas do PEI. A pequena diferença entre os dois pode ser explicada pelo fato de que no PETAR existem áreas de piqueniques onde as famílias podem passar o dia sem necessariamente se embrenharem em trilhas. Já no caso do PEI o propósito das visitas é exatamente percorrer as trilhas e visitar as cavernas. Note-se que nos finais de semana, segundo relato dos funcionários dos dois parques, há famílias que moram na região que vão passear na sede do parque e realizam uma trilha.

Em ambos os parques, $100 \%$ dos pesquisados afirmaram que percorreram as trilhas com guias/monitores. De fato, a regra em ambos os parques é que as trilhas sejam percorridas com 
guias/monitores. Em geral a regra é respeitada, porém, há relatos ${ }^{4}$ de que no PETAR os percursos são feitos irregularmente por visitantes que "já conhecem o parque" e entram nas cavernas sem o devido acompanhamento ou autorização. No PEI não há relatos de atividades realizadas sem o acompanhamento de monitores.

O gráfico 2 mostra que cerca de $60 \%$ dos pesquisados do PETAR lancharam nas trilhas contra $80 \%$ dos do PEI. Os visitantes dos parques são orientados a levar lanches para passarem o dia nas trilhas que levam à cachoeira ou cavernas já que é comum serem percorridas duas ou três trilhas no mesmo dia, a fim de otimizar o tempo. Ainda assim, no caso do PETAR, nota-se que muitos visitantes optam por percorrer as trilhas sem nenhum tipo de alimento.

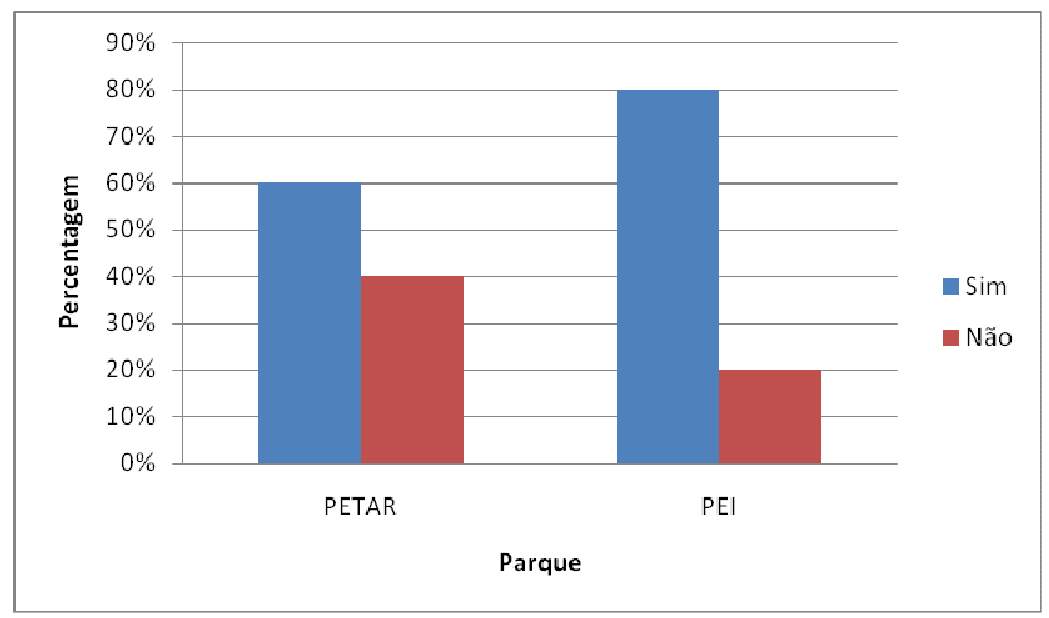

Gráfico 2 - Percentagens dos Turistas Entrevistados que Comeu na Trilha do PETAR e PEI Fonte: Dados da pesquisa

Entre aqueles que levaram lanche, $15 \%$ dos entrevistados no PETAR afirmaram que o lixo caiu em lugar de difícil acesso contra 100\% dos entrevistados do PEI que afirmaram ter recolhido e lavado o lixo consigo.

\footnotetext{
${ }^{4}$ Relatos informais de um funcionário do IF, de um guia do PETAR e de um funcionário de uma pousada. Este disse que é possível entrar nas cavernas mesmo à noite, que era só marcar com um guia. O guia do PETAR confirmou da possibilidade e o funcionário do IF disse que é possível acontecer diante da falta de guardas.
} 
Em geral, os visitantes dos parques que querem fazer atividades de ecoturismo são orientados pelos monitores a levarem o lixo de volta e jogarem em local apropriado ao retornarem das trilhas. Além disso, em geral, os visitantes têm demonstrado ter noção de que não se deve jogar as embalagens dos alimentos nas trilhas. Há, porém, visitantes que jogam lixo inadvertidamente nas trilhas, principalmente no PETAR. Na área da sede do Núcleo Santana, apesar de haver latas de lixo espalhadas, havia embalagens e latas jogadas na trilha. O mesmo cenário foi possível ser observado nas estadas no entorno do parque com muito lixo jogado no chão.

Conforme o gráfico 3, cerca de $70 \%$ dos entrevistados do PETAR afirmaram terem percorridos a trilha em grupos de 7 a 10 pessoas contra 90\% no PEI. O número de pessoas que acompanham o guia/monitor não está determinado pelo plano de manejo de ambos os parques. No PEI há orientação dos monitores de que nas cavernas que têm difícil acesso o número não ultrapasse 6 pessoas, porém, nas cavernas mais fáceis, é permitido a entrada de até 10 pessoas. Já no PETAR, os grupos que acompanham os guias possuem uma média de 7 a 10 pessoas. Durante a alta temporada, porém, há grupos com mais de 10 pessoas acompanhando um guia, o que pode ser explicado pelo fato de haver mais visitantes que vêm de excursão, além de maior número de pessoas, aumentando a possibilidade de se formarem grupos maiores e ratearem o valor da diária do guia.

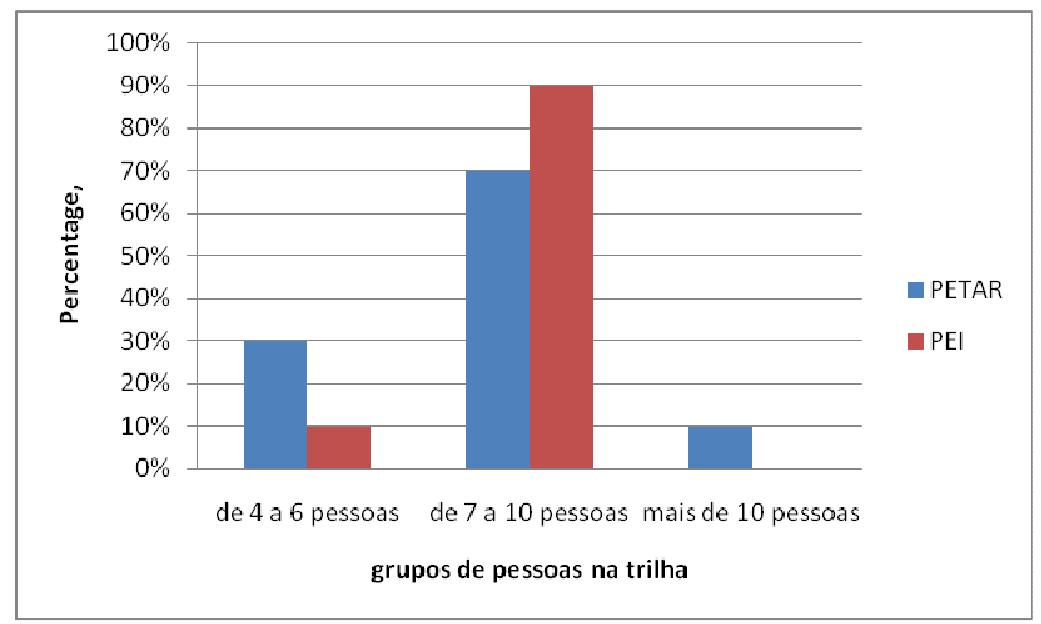

Gráfico 3 - Tamanho dos Grupos de Pessoas Caminhando nas Trilhas do PETAR e PEI Fonte: Dados da Pesquisa 
Os entrevistados também responderam a questão de se os guias/monitores deram mais informações sobre os pontos turísticos (trilhas, animais, cavernas, curiosidades, etc). No caso do PETAR $70 \%$ afirmaram que não receberam qualquer informação contra apenas $20 \%$ no caso do PEI.

Em geral, a função do guia/monitor é de guiar os visitantes pelas trilhas desconhecidas e fornecer informações acerca das atrações turísticas dos parques. No PEI os monitores mostraram-se bastante familiarizados com a região do parque, fornecendo informações sobre a fauna, a flora, a história do parque, sobre as formações das cavernas entre outras curiosidades. Note-se que muitos monitores do PEI foram ex-funcionários da fazenda Intervales da Banespa Mineração e, por isso, moram na região há muito tempo e conhecem o parque. Aliado aos cursos de capacitação e ao acompanhamento dos pesquisadores no parque, acabam aprendendo sobre a fauna e flora do parque e disseminam seus conhecimentos para os visitantes. No PETAR a situação é diferente. A maior parte dos guias são moradores da região e submeteram-se a cursos técnicos para se tornarem guias. Alguns demonstraram ter conhecimento sobre o parque e espontaneamente explicavam sobre os pontos turísticos do parque. Outros se limitaram a guiar, sem nada explicar. Muitos visitantes do PETAR disseram que tinha muita gente dentro da caverna e só se lembravam do guia explicar poucas coisas sobre as formações das cavernas.

Os turistas foram questionados sobre os serviços que os parques oferecem (guias, hospedagem, restaurante, lojas de souvenirs, etc.). Entre os turistas do PETAR 60\% afirmaram que os serviços agradaram contra $50 \%$ dos entrevistados no PEI.

Os parques apresentam características diferentes no tocante aos serviços destinados aos visitantes. No PEI a hospedagem (com capacidade para 100 pessoas) pertence à Fundação Florestal, administradora do parque, e o restaurante é administrado pela Coopervales (Cooperativa de Serviços Múltiplos de Ribeirão Grande e Intervales, criada em 1995, reúne ex-funcionários da Fundepag, empresa que contratava parte da mão-de-obra do parque.) que tem a concessão e fornece mão-de-obra para outros serviços locais. Os monitores são muito bem treinados e são muito elogiados pelos visitantes. Há ainda, na sede, piscina natural, parque infantil, quadra de esporte, campo de futebol tradicional e suíço, cancha de bocha, 
quiosques e churrasqueiras. Quanto aos souvenirs, há uma pequena loja, administrada pela Coopervales, que comercializa peças artesanais da região, mochilas, camisetas, e alguns produtos de higiene.

Metade dos visitantes que responderam ao questionário disseram não ter gostado dos serviços pelas mais diversas razões: a) a hospedaria não é confortável; b) cansaram-se de comer sempre no mesmo restaurante; c) falta de variedade na oferta de souvenirs. Todos elogiaram os serviços prestados pelos monitores.

No PETAR, não há estrutura de hospedagem ou restaurante dentro do parque, mas há muita oferta de pousadas que oferecem alimentação para os hóspedes. Havia uma área de camping na sede do Núcleo Santana, mas foi desativada em 2005. Não há restaurantes, apenas um bar/lanchonete precário nas imediações. Os souvenirs, quando existem, limitam-se a camisetas do parque. Há procura por parte dos visitantes, mas não há oferta. A maioria dos visitantes afirmou que os serviços agradaram, reclamaram, porém, da: a) falta de restaurantes e/ou lanchonetes; b) falta de oferta de souvenirs; c) o preço da diária cobrado pelos guias. Vale lembrar que não há dentro do PETAR hospedagem nem restaurantes.

O gráfico 4 mostra a opinião dos turistas entrevistados sobre o grau de conservação dos parques. O PEI, em geral, apresenta bom estado de conservação. As cavernas apresentavam razoável estado de conservação, contudo algumas delas apresentavam o escurecimento dos espeleotemas resultantes da fumaça das carbureteiras. O PETAR apresenta razoável estado de conservação, contudo a caverna Santana, do Núcleo Santana, apresenta muita deterioração, com o escurecimento excessivo dos espeleotemas causados pela fumaça das carbureteiras, além de evidências de pisoteamento de vegetações ao redor de algumas trilhas mais visitadas. 


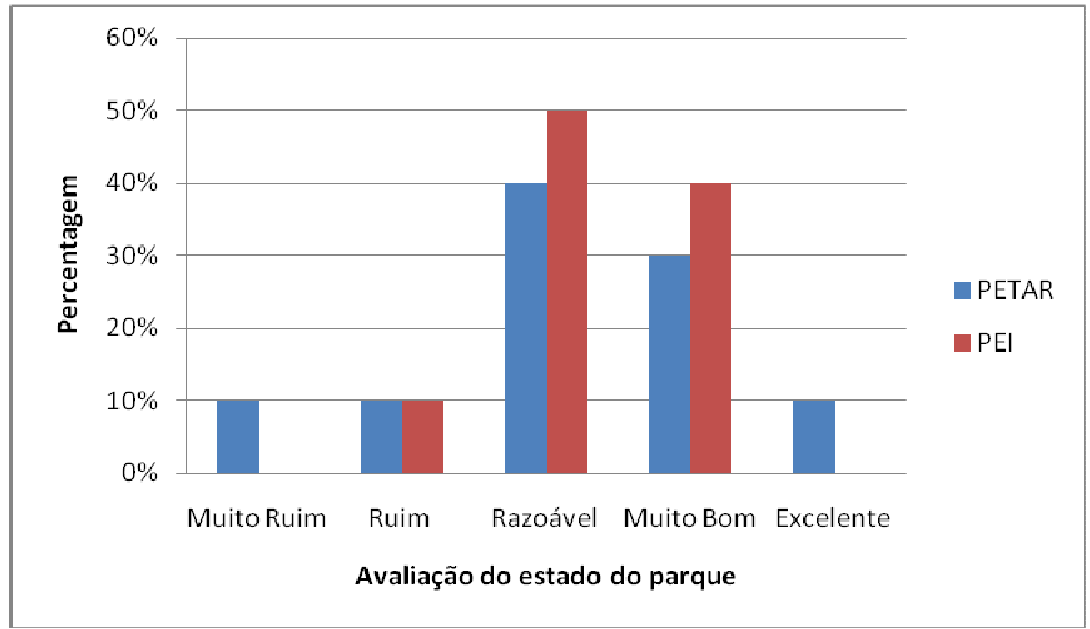

Gráfico 4 - Avaliação dos turistas do estado de conservação do PETAR e PEI Fonte: Dados da Pesquisa

Conforme o gráfico 5, em relação aos guias/monitores entrevistados, no PETAR, 60\% trabalham com essa atividade entre 4 e 7 anos, enquanto que no PEI, 60\% trabalham com o parque há mais de 7 anos.

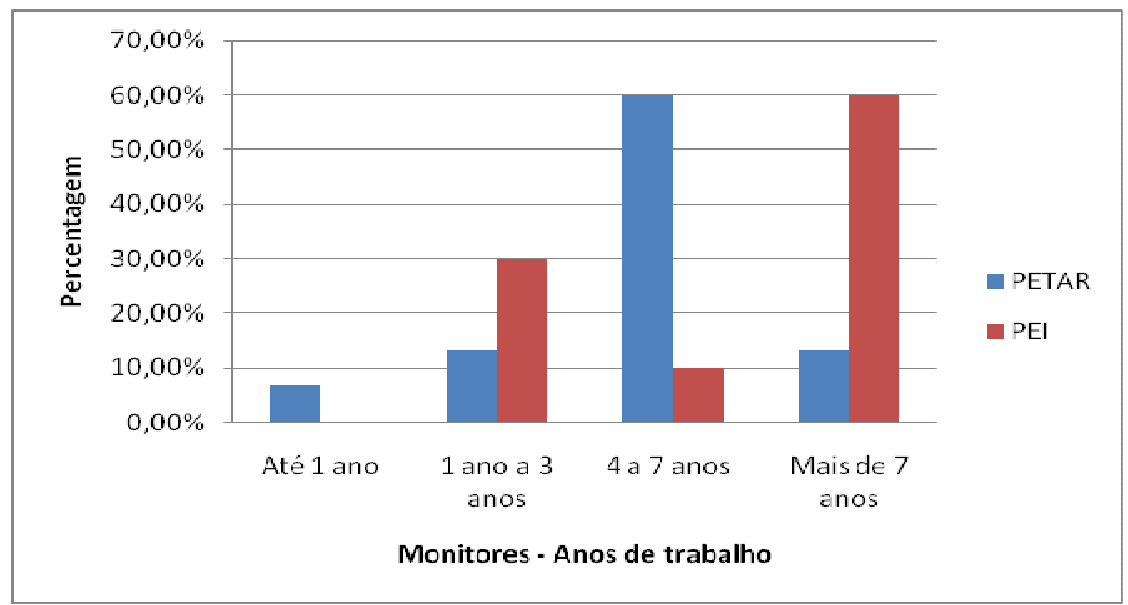

Gráfico 5 - Anos de Trabalho no PETAR e PEI como Guias/Monitores Fonte: Dados da Pesquisa 
Os dados mostram que no caso do PETAR houve um aumento do número de guias/monitores nos últimos 7 anos, principalmente há cerca de 4 anos, quando começou a aumentar o interesse pela região. São cerca de 170 cooperados dos quais 60 estão na ativa. Há alguns monitores que são funcionários do IF, outros da FF, porém, grande parte é guia independente. No caso do PEI, os monitores concursados, funcionários da Fundação Florestal são antigos, muitos ex-trabalhadores da Fazenda Intervales, e os cooperados são mais recentes.

Os guias/monitores foram questionados se nasceram na região. No caso do Petar 73,3\% responderam que sim contra $60 \%$ no PEI. Além disso, também foram questionados se moram na região. Neste caso, $100 \%$ afirmarem viver na área do entorno parque.

Os dados, em conjunto, demonstram que em ambos os casos os parques funcionam como fixadores destes moradores na região.

No caso do PEI, o coordenador dos monitores Eliseu Cordeiro de Paula, funcionário da Fundação Florestal, é gaúcho, mas vive há 21 anos na região do PEI. Trabalhou na Fazenda Intervales, de propriedade da Banespa Mineração e foi coordenador da fábrica de conservas de palmito da empresa. Sabe-se que muitos dos que trabalham atualmente no PEI foram extrabalhadores da mineração e, com a transformação da área em parque, muitos foram beneficiados e passaram a trabalhar como monitores porque conheciam bem o local. Tanto no PEI quanto no PETAR muitos moram na região até porque não é possível morar longe já que o parque é relativamente isolado.

Em ambos os parques, $100 \%$ dos guias/monitores afirmaram ter recebido treinamento para trabalhar com os visitantes, mas apenas $26,7 \%$ dos guias/monitores entrevistados no PETAR afirmaram participar de palestras, seminários e novos treinamentos, contra $80 \%$ no PEI.

Em ambos os parques é obrigatório um curso de capacitação para operar como guia/monitor. No PEI, os monitores recebem treinamento, participam de palestras além de terem contato constante com os pesquisadores que, ao conduzirem suas pesquisas científicas, têm sempre a companhia de um monitor que acabam aprendendo e repassam os conhecimentos adquiridos aos visitantes. 
Por exemplo, o monitor do PEI Renato Laurindo Paiva, da Coopervales, trabalha há 9 anos no parque e tem um conhecimento sobre morcegos adquirido por meio de um pesquisador da Unicamp, que realizava estudo sobre o animal e as plantas solanáceas, das quais se alimentam. Outro monitor, Luiz Avelino Ribeiro, funcionário da Fundação Florestal, possui conhecimento excepcional sobre a fauna da região, conhecimento adquirido por conta dos pesquisadores brasileiros e dos observadores ${ }^{5}$ de aves internacionais, além do estudo de livros sobre o tema.

A estatística indica que a reciclagem de conhecimentos não vem ocorrendo no PETAR, mas que poderiam ser feitas através de palestras. A participação dos monitores/guias em palestras e seminários é importante porque são eles que têm contato direto com os visitantes e, mais do que meros monitores/funcionários, funcionam como educadores ambientais também.

Os guias/monitores foram questionados sobre o relacionamento com os administradores dos parques. Entre os pesquisados do PETAR, 40\% afirmaram haver diálogo com a direção contra $90 \%$ no PEI.

O administrador do PETAR tem a responsabilidade de administrar uma região muito extensa, o que dificulta o contato com todos os monitores, mesmo assim os guias que tiveram contato com o gestor do PETAR afirmam que o mesmo é extremamente aberto a demandas, reivindicações. No caso do PEI, o administrador passa grande parte do tempo no parque o que facilita o contato com os monitores, levando-se em consideração também que seu número é menor que no PETAR, o que possibilita maior eficácia no atendimento das eventuais demandas.

O gráfico 6 mostra a relação trabalhista do guias/monitores com os parques. A maior parte dos guias do PETAR são cooperados, contudo, foi constatado que há guias que atuam de forma independente e autônoma. No PEI 6 são concursados e 4 cooperados.

5 O PEI foi incluído no roteiro internacional de observação de aves, fato que aumentou o número de grupos de visitantes estrangeiros. 


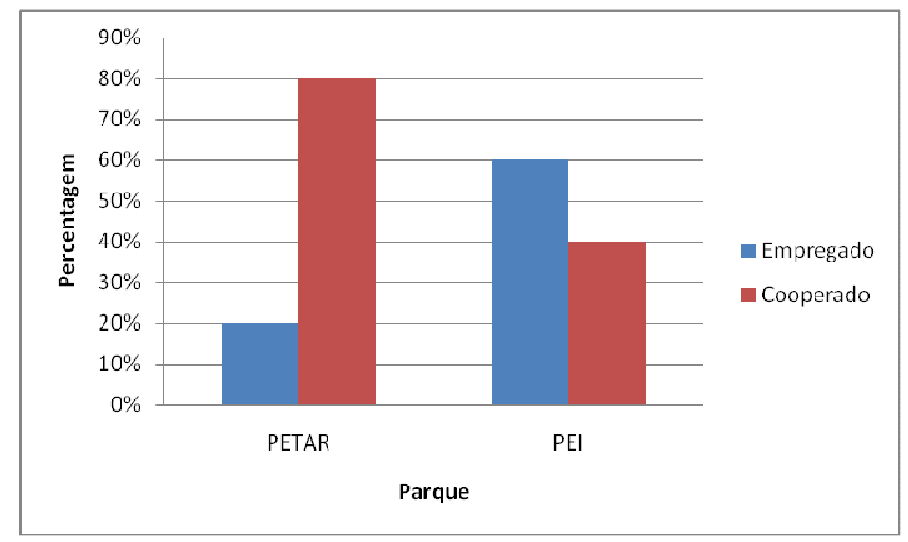

Gráfico 6 - Relação Trabalhista de Guias/Monitores Entrevistados no PETAR e PEI Fonte: Dados da Pesquisa

Cerca de $86,7 \%$ dos guias do PETAR afirmaram que o parque é sua fonte primária de renda, contra $100 \%$ no PEI. No PETAR, para aqueles que trabalham como guia esta é fonte primária de renda. Deve-se considerar que dado o número de cooperados é pouco representativo o número de guias beneficiados pelo turismo. No PEI, todos os monitores vivem do turismo. $\mathrm{Na}$ Coopervales, para tudo o que é ganho pela cooperativa através do restaurante, dos monitores, e da limpeza da hospedaria, entre outros, existe um valor fixo para cada cooperado que trabalha.

É preciso considerar, porém, que o ecoturismo é sazonal e reflete os momentos de alta e baixa temporada do turismo em geral. Diante dessa sazonalidade, muitos monitores novos, que receberam treinamento para se tornarem monitores, acabam por abandonar a monitoria. Há um problema em fixar novos monitores para que haja a substituição dos monitores antigos que em breve se aposentarão.

Finalmente os guias/monitores foram questionados se eles são em número suficiente para atender a demanda de turistas. No PETAR, 100\% afirmaram que sim contra $70 \%$ no PEI.

No caso do PETAR, é claro que há uma super oferta de guias. Há muita concorrência e a profissão é encarada como negócio e os guias pedem para que sejam indicados aos amigos, muitas vezes entregando cartões. Já no PEI, muitos não encaram sua profissão como um 
negócio, e, apesar da menor quantidade de monitores, a maioria considerou suficiente para responder à atual demanda de visitantes, mas é provável que os que lá estejam não queiram dividir o espaço com potenciais concorrentes, pois diminuiria a fatia de seus ganhos. Note-se que há consciência entre os monitores do PEI, pois sabem da necessidade da inserção de novos monitores uma vez que alguns dos monitores antigos irão se aposentar em breve.

Se partirmos de uma premissa de que o PEI tem, de forma geral, um estado de conservação superior ao de PETAR, vemos que os questionários revelam quatro fatores importantes que podem explicar, ao menos parcialmente, esta situação: nível de escolaridade dos visitantes, grau de controle das visitações, treinamento dos guias/monitores e diálogo com a administração dos parques.

O PEI, além de ser relativamente pouco conhecido como destino ecoturístico, tem quase como premissa da sua visitação a estadia dentro das hospedarias do parque. Desta forma, o parque tem atraído um público com nível sociocultural diferenciado que tende a apreciar os valores embutidos em uma visitação responsável.

Além disso, como o PEI tem uma capacidade de recepção de visitantes consideravelmente menor que a do PETAR (seja pelo número de monitores, seja pela capacidade física de recepção de visitantes) tem-se uma visitação altamente controlada, onde alguns visitantes percorrem trilhas auto-guiadas próximas das hospedarias e, no mais, percorrem as trilhas em grupos de até 10 pessoas com estrito acompanhamento dos monitores. Por outro lado, o Núcleo Santana absorve um número muito grande de visitantes que vêm em ônibus de excursão. Logicamente que o grande fluxo de visitantes, atrelado às necessidades dos guias que, na prática, concorrem entre si pelo trabalho, gera uma exploração mais desordenada do espaço.

Ao mesmo tempo, o reduzido número de monitores do PEI ajuda a manter uma equipe motivada que constantemente se recicla e permanece comprometida em seu zelo pelo parque. Vale ressaltar que ainda que um grupo de visitantes de uma excursão venha com um guia externo, deverá ser acompanhado por um monitor do PEI. No PETAR o excesso de guias acaba funcionando como um mecanismo perverso de concorrência onde a principal motivação 
daqueles que ainda acreditam na possibilidade de dali tirarem seu sustento, é a de estar sempre à disposição de potenciais visitantes. Assim, não há motivação em se aperfeiçoar ou transmitir o zelo pelo parque.

Finalmente, por mais que o gestor do PETAR possa se colocar aberto ao relacionamento com os guias e a comunidade, ele tem sob sua responsabilidade uma unidade de conservação dividida em núcleos de visitação distantes uma das outras, além do que, a sede do PETAR fica no centro do município de Apiaí, e não dentro da área do PETAR, enquanto que o gestor do PEI pode se dedicar ao parque sem grandes deslocamentos, pois a sede administrativa fica dentro da área do parque. Essa proximidade física certamente contribui para uma gestão mais eficiente daquele espaço.

Desta forma, a pesquisa de campo indica que claramente há uma exploração turística desordenada do PETAR especialmente em comparação ao PEI levando a verificar a incidência da tragédia dos comuns no PETAR, mas não no PEI. Portanto, é fundamental entender comparativamente por quê o fenômeno ocorre no PETAR mas não no PEI.

Agrupamos em dois grandes fatores a diferença entre os dois parques: infraestrutura turística e modelos jurídicos de gestão dos parques. Por infraestrutura turística entende-se os meios de hospedagem, alimentação e acesso aos atrativos locais o que inclui facilidade física de chegar a eles e disponibilidade de monitores. Já por modelo jurídico de gestão dos parques entende-se o modelo estrutural e organizacional do trabalho de gestor do parque que é vinculado ou ao Instituto Florestal ou à Fundação Florestal.

O que se observa na prática, no caso do PETAR, é a ocorrência da tragédia dos comuns. Toda a população de uma região essencialmente empobrecida (Vale da Ribeira) aproveita-se da área comum, o PETAR, para explorar o potencial turístico da maior concentração de cavernas do Estado de São Paulo (cerca de 280). Como não há limitação e ordenamento da atividade, são abertos hotéis, pousadas, campings, restaurantes, e todas as outras atividades comerciais que vêm junto com o turismo como mercados, agências, etc., para explorar este potencial.

A corrida pelo turista leva ao crescimento desordenado da cidade e a prestação de um serviço que nem sempre preza por altos padrões de qualidade e segurança. De certa forma, a cidade de 
Iporanga, Apiaí e outras podem até eventualmente acomodar este crescimento urbano o que ainda exigirá investimentos de infraestrutura para lidar com o aumento de carga no sistema elétrico e de saneamento.

Entretanto, pela tragédia dos comuns, a exploração desenfreada e desorganizada da área tende a esgotar o potencial turístico do PETAR levando não só a destruição de um patrimônio ecológico do Estado de São Paulo como a ruína econômica de uma região já problemática.

Do ponto de vista de infraestrutura turística, tal deterioração vem ocorrendo fruto de uma visitação desordenada que permite um fluxo crescente de ônibus de turismo, especialmente dos turistas de um dia, ou mesmo do crescente número de pousadas que, embora estacionado, tende a voltar a crescer.

Já no caso do PEI, a limitada infraestrutura turística do parque, seja pelo número de leitos, seja por capacidade de aceitação de visitantes que irão ou não realizar visitas monitoradas leva a um impacto negativo significativamente menor e consideravelmente melhor controlado. $\mathrm{Ou}$ seja, se levarmos em conta apenas a capacidade em termos de leito, o PEI poderia receber 36.000 visitantes por ano contra 270.000 visitantes no caso do PETAR (considerando 100\% de ocupação todos os dias do ano).

É lógico que no caso do PEI o destino é bem menos conhecido que no caso do PETAR, mas, de qualquer forma, isto é insuficiente para compreender as diferenças entre os parques mesmo porque o PETAR, provavelmente, é mais conhecido porque são mais estabelecimentos comercias divulgando o parque e concorrendo entre si pela simpatia do turista.

Como notado, o PEI está vinculado à FF enquanto que o PETAR está vinculado ao IF. Como a FF tem personalidade jurídica distinta ela tem uma significativa autonomia na gestão do parque. Já o IF não tem autonomia administrativa e está estritamente submetido ao controle político, legal e orçamentário da SMA.

O fato da FF e do IF possuírem natureza jurídica distinta, ou seja, enquanto a primeira é uma fundação pública, a segunda é um órgão público, é de extrema importância para se compreender um aspecto crucial no modo de gestão de seus respectivos parques pois 
determina a maior autonomia administrativa de um em relação ao outro. Tal autonomia permite que a FF tenha maior poder discricionário em relação à administração do PEI, e isso reflete diretamente na atuação do gestor do parque, que pode ter maior mobilidade na realização de atividades e flexibilidade no momento de contratar, executar cursos e promover parcerias com organizações civis. Claro que deve seguir o ordenamento referente às atividades públicas, como a licitação, contudo, seu poder de decisão pode ser mais célere e menos burocrático em relação ao PETAR.

Ou seja, em termos práticos a FF tem incentivos para gerar modelos de gestão que garantam a auto-suficiência do parque, mesmo porque os recursos gerados no parque ficam com a FF, o que provavelmente implica na probabilidade de retorno ao próprio PEI. Além disso, em termos práticos a FF está próxima ao objeto de gestão e, por conta disto, pode ter mais agilidade na geração de modelos alternativos, como o caso da cooperativa.

Isto significa que o gestor do PETAR não tem autonomia para gerar despesas que não estejam provisionadas no orçamento do Estado de São Paulo e que toda receita eventualmente gerada por qualquer iniciativa no parque irá retornar ao orçamento do Estado de São Paulo e não, necessariamente, ao próprio parque.

Em outras palavras, a presente estrutura jurídica amarra o gestor do PETAR que não tem, diante de si, mecanismos para gerir de forma independente. O resultado é que o PETAR tornou-se refém da tragédia dos comuns e não há nas mãos do gestor do parque, dada a presente situação, mecanismos legais e econômicos para reverter esta situação. Além disso, o PETAR é apenas uma das unidades de conservação do IF que tem sob sua administração 851.910.03 hectares de florestas naturais e implantadas, abrigadas sob a forma de 86 Unidades de Conservação, que incluem desde Florestas Estaduais, Estações Experimentais, Reservas e Parques Estaduais, além de Viveiros Estaduais e o Horto Florestal, sendo responsável pelo resguardo de 3,4\% do território paulista, incluindo $10 \%$ do que restou da biodiversidade do Domínio da Mata Atlântica. 


\section{Conclusão}

A análise dos dados e do resultado da pesquisa de campo nos leva a concluir que o PETAR está sofrendo um processo de deterioração de suas cavernas abertas à visitação e de seu entorno fruto do turismo desordenado, configurando assim a incidência da tragédia dos comuns. Já no caso do PEI, foi constatada uma visitação mais controlada e limitada e, portanto, um grau de preservação do complexo turístico bastante superior.

Constatamos que dentre os diversos fatores que podem explicar as diferenças entre os parques, essencialmente, podem ser divididos entre diferenças em infraestrutura turística e modelo jurídico de gestão dos parques. Sendo que o PEI tem uma infraestrutura turística limitada, o que naturalmente limita as visitações e é submetido à FF, o que significa autonomia de gestão. Já o PETAR, tem assistido um crescimento desordenado e exploratório da sua infraestrutura turística, o que tem levado a deterioração de cavernas e do entorno do parque. Além disso, o gestor do parque tem pouca autonomia na sua gestão, dadas as amarras jurídicas de ligação com o IF que, por sua vez, é controlado pela SMA e suas dotações orçamentárias.

Esta pesquisa mostrou que as visitações aos parques, seja na forma de ecoturismo, seja para simples recreação, podem causar resultados díspares, não por causa da natureza da atividade, mas pela forma como é feita a gestão do parque. A tendência a imputar a responsabilidade exclusivamente ao usuário do parque é um mito, pois a grande lição do PETAR é que quando aquele gere inadequadamente a natureza, na medida em que permite a exploração da área do parque por parte de monitores cuja simples informação da finalidade da criação dos parques estaduais é deficiente, esta tende a deteriorar-se rapidamente face à falta de planejamento, instrumentos regulamentares e fiscalizações eficientes.

Desta forma, faz-se a inclusão das comunidades em atividades que, concomitantemente, lhes provenha de renda e os obrigue (através de incentivos econômicos e legais) a preservar o parque para assegurar sua renda futura e, logicamente, a conservação dos ecossistemas dos parques. Ou seja, nos parece que este é o caso de PEI que, através da solução da exploração 
através de uma cooperativa sob a tutela de um plano de gestão (mecanismo legal) e sob a supervisão da FF, tem conseguido conciliar o ecoturismo com a preservação ambiental.

Esta pesquisa não tem a pretensão de ser conclusiva, mas sim um conjunto de informações que estão em processo de aperfeiçoamento. Entretanto, devemos considerar que no fundo toda área pública enfrenta o dilema da exploração racional e a questão de como evitar a tragédia dos comuns.

Em nosso caso vimos que o PETAR sofre de problemas sérios em sua gestão que o levam a tragédia dos comuns e no caso do PEI isso não ocorre visto diferenças jurídicas e limitações de uso do parque.

No fundo, nos parece que o PETAR é mal explorado e o PEI sub-explorado. No caso do PETAR, a saída certamente é passar a gestão de uma fundação específica para o PETAR. Ou seja, não estamos sugerindo que ele passe a gestão da FF, que acabaria dividindo esforços na gestão do parque, mas sim de uma fundação com status jurídico equivalente ao FF que, com mais autonomia, poderia começar a agir para impedir que a tragédia dos comuns torne-se definitivamente irreversível.

Já em relação ao PEI, embora o meio ambiente esteja sendo aproveitado e de forma limitada, seja gerada renda para a população local, o parque tem potencial para gerar mais empregos e renda de forma racional. Em outras palavras, se mecanismos adequados de planejamento forem ativados, uma parceria entre a FF e a Prefeitura de Ribeirão Grande e outras da região, poderia levar a construção de um modelo que gerasse mais turismo na região com mais pousadas, hotéis e restaurantes.

\section{Referências}

ALLEGRINI, Claudia Queiroz Sallouti. Gestão do programa de uso público no Parque Estadual do Alto Ribeira - PETAR: um estudo de caso de implantação de sistema de cobrança de ingressos e serviços.1999. 179f. Dissertação (mestre em Ciência Ambiental). Programa de Pós-Graduação em Ciência Ambiental - PROCAM/ USP, São Paulo, 1999.

BRIASSOULIS, H., "Sustainable Tourism and the Question of Commons" Annals of Tourism Research, 29, 4. 2002 
CEBALLOS-LASCURÁIN, Héctor. Ecoturismo;naturaleza y deserrollo sistenible. México. Editorial Diana. 2005.

DOINICAR; S; CROUCH, G; e LONG, P; "Environment-friendly Tourists: What Do We Really Know About Them?" Journal of Sustainable Tourism, 16, 2, 2008.

GÖSSLING, C.; HALL, M.; WEAVER, D.B. Sustainable Tourism Futures: Perspectives on Systems, Restructuring, and Innovations. New York/Londres. Routledge, 2009.

HAWKINS, D. E.; KAHN, M. M. Oportunidades para o turismo ecológico nos países em desenvolvimento, In THEOBALD, W. (org.) Turismo global. São Paulo, Senac, 2001.

KINKER, S. M. S. O Ecoturismo como uma das estratégias para a conservação da natureza em Parques Nacionais Brasileiros - Estudo de caso dos Parques Nacionais de Aparados da Serra e Caparaó. 1999. 429f. Dissertação (Mestrado em Ciência Ambiental). Programa de Pós-Graduação em Ciência Ambiental - PROCAM/ USP, São Paulo, 1999.

KNAFOU. R. Turismo e território. Por uma abordagem científica do turismo. In: RODRIGUES, A. A. B. (Org.). Turismo e Geografia: Reflexões teóricas e enfoques regionais. São Paulo, Hucitec, 1996.

MACHADO, A. Ecoturismo: um produto viável. A experiência do Rio Grande do Sul. Rio de Janeiro, Senac Nacional, 2005.

MARANGONI, A. M. M. C., Questionários e entrevistas - algumas considerações. In: VENTURI, L.A.B. (Org.). Praticando Geografia - técnicas de campo e laboratório. São Paulo, Oficina de Textos, 2005. P.167-174.

MEDAUAR, O. Direito Administrativo Moderno. São Paulo, Editora Revista dos Tribunais, 1996.

RODRIGUES, Adyr B. (org.). Ecoturismo no Brasil: possibilidades e limites. São Paulo: Contexto, 2003.

RUSCHMANN, Doris van de Meene. Turismo Planejamento Sustentável: A proteção do meio ambiente. Campinas, SP: Papirus, 1997.

SÃO PAULO. Secretaria de Estado do Meio Ambiente. Atlas das Unidades de Conservação Ambiental do Estado de São Paulo. São Paulo, 2000.

SÃO PAULO. Secretaria do Meio Ambiente. Fundação Florestal. Parque Estadual Intervales: plano de gestão ambiental, fase1. São Paulo: Fundação Florestal, 1998. 231p.

SWARBROOKE, John. Turismo Sustentável: meio ambiente e economia, vol. 2. São Paulo: Aleph, 2000.

WEARING, Stephen e NEIL, John. Ecoturismo: Impactos, potencialidades e possibilidades. Barueri, SP: Manole, 2001.

Recebido em: 29/04/2011

Aprovado em: 28/11/2011 (1 ${ }^{\mathrm{a}}$ versão) $18 / 01 / 2012$ ( $2^{\mathrm{a}}$ versão) 